\title{
Organic and inorganic decomposition products from the thermal desorption of atmospheric particles
}

\section{B. J. Williams et al.}

Correspondence to: Brent J. Williams (brentw@wustl.edu)

The copyright of individual parts of the supplement might differ from the CC-BY 3.0 licence. 


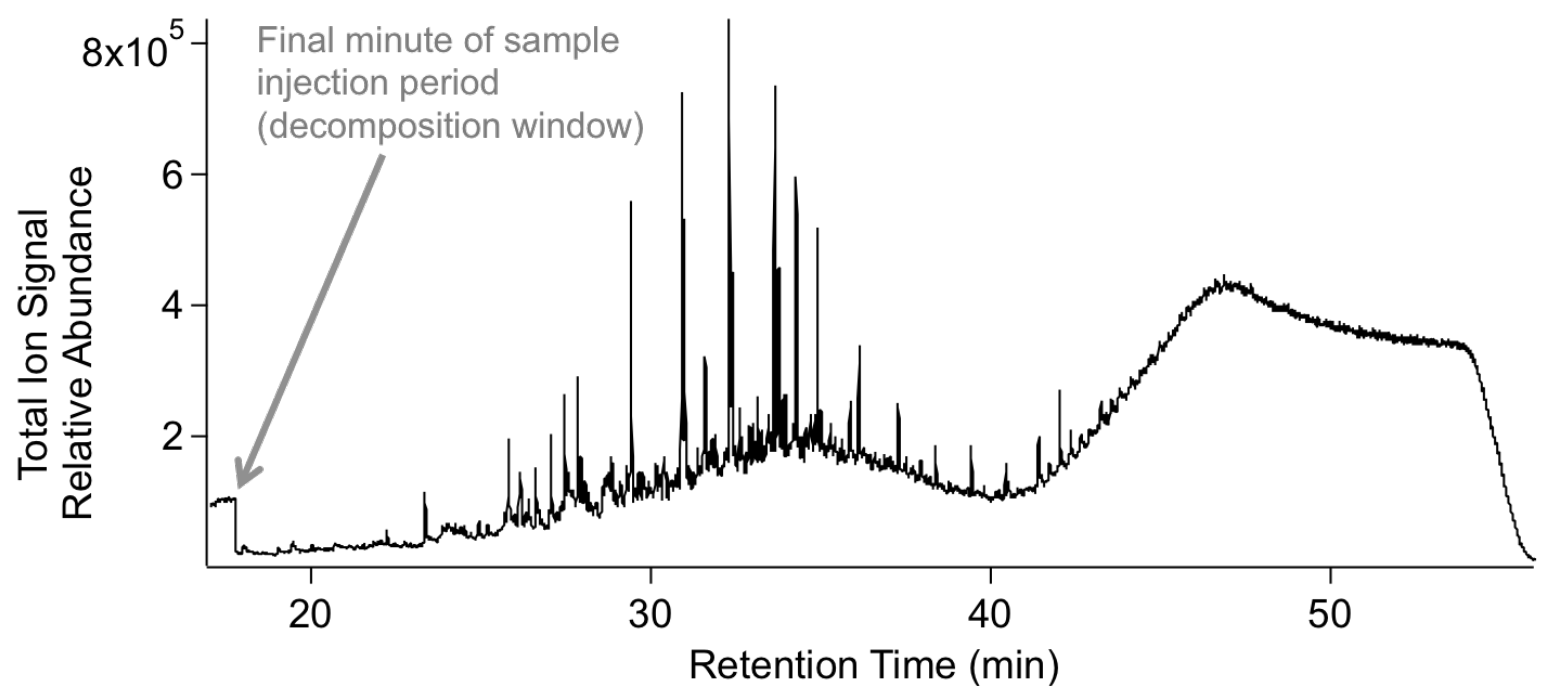

Figure S1. Example TAG chromatogram during SOAR 2005 in Riverside, CA. During this study, the final minute of the decomposition window was captured, but not the entire CTD cell injection period as will be the method utilized in future work (as it was applied during SLAQRS 2013). 

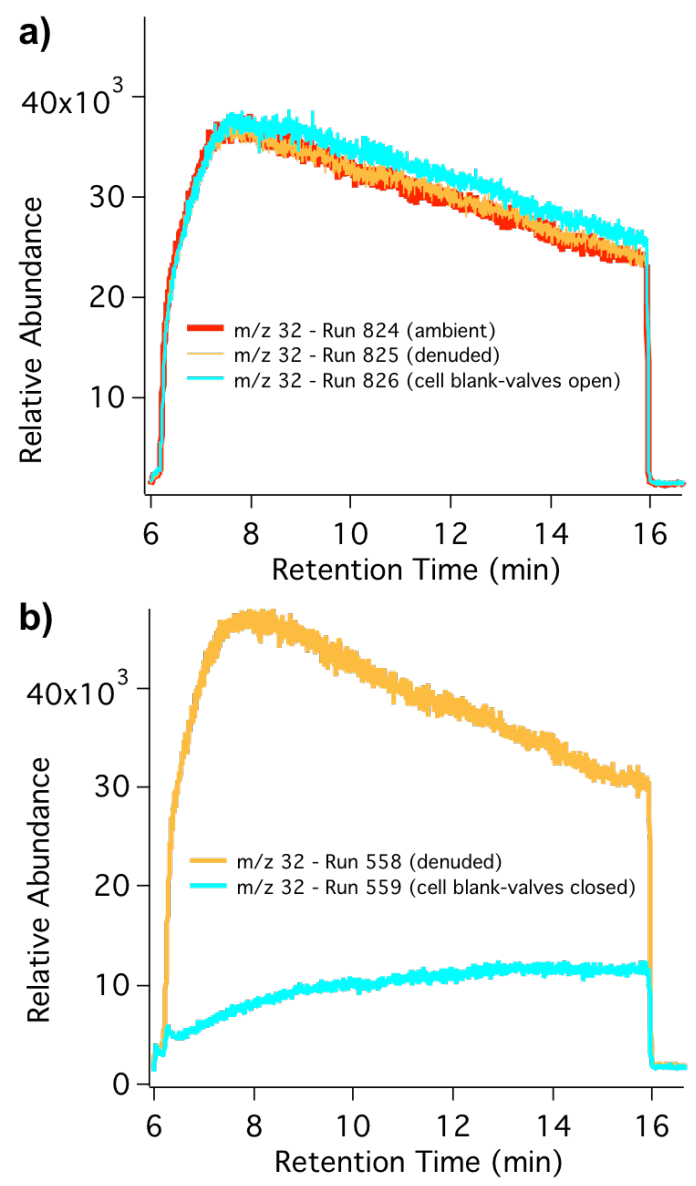

Figure S2. Air signal $(\mathrm{m} / \mathrm{z} 32)$ present in the sample introduction time period when (a) sample valves are opened, compared to when (b) sample valves remain closed during a re-desorption blank (light gray). It is observed that $m / z 32$ during the sample injection period (6-16 minutes) is dramatically reduced if sample valves remain closed from the previous desorption cycle and new air is not allowed to enter the helium-filled CTD cell. A majority of the air signal during the sample injection period is likely due to dead volume spaces that are inefficiently purged with helium prior to sample delivery to the GC column. 


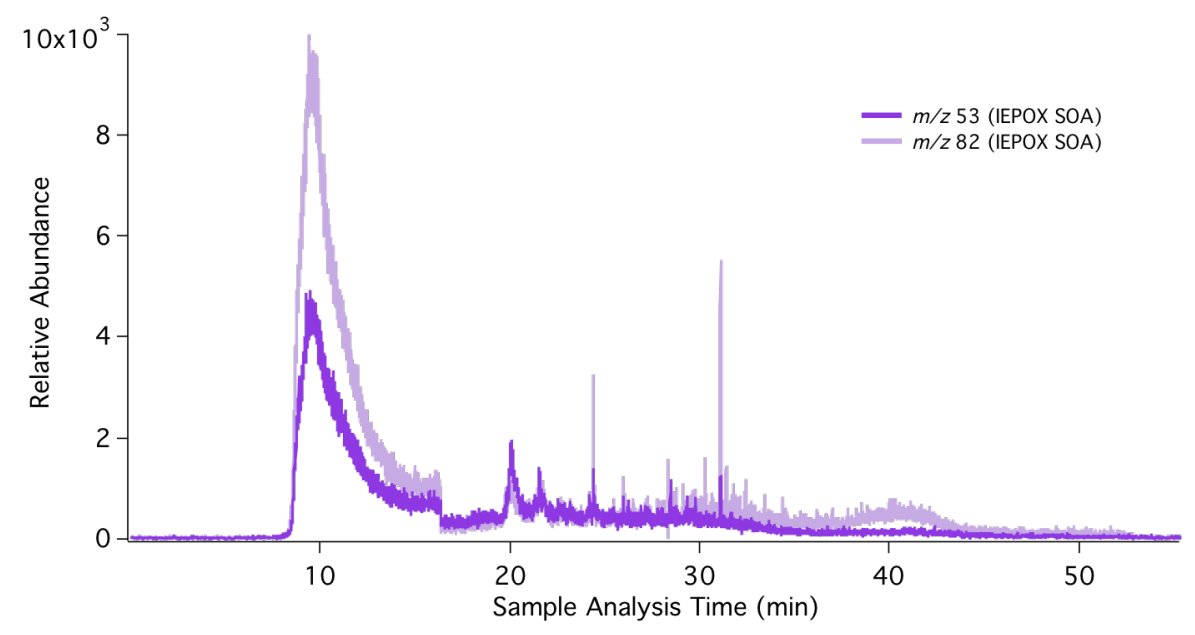

Figure S3. Single ion chromatogram signals for $m / z 53,82$ across the entire sample analysis period, incorporating the thermal decomposition window (6-16 $\mathrm{min}$ ) and the resolved compound window (16-50 $\mathrm{min})$. While a majority of the signal for these presumed isoprene-derived SOA marker ions is present in the decomposition window, there are individual compounds present that could also be used as source marker molecules. This data is from the same sample that is displayed and discussed in Fig. $3 e, f$. 

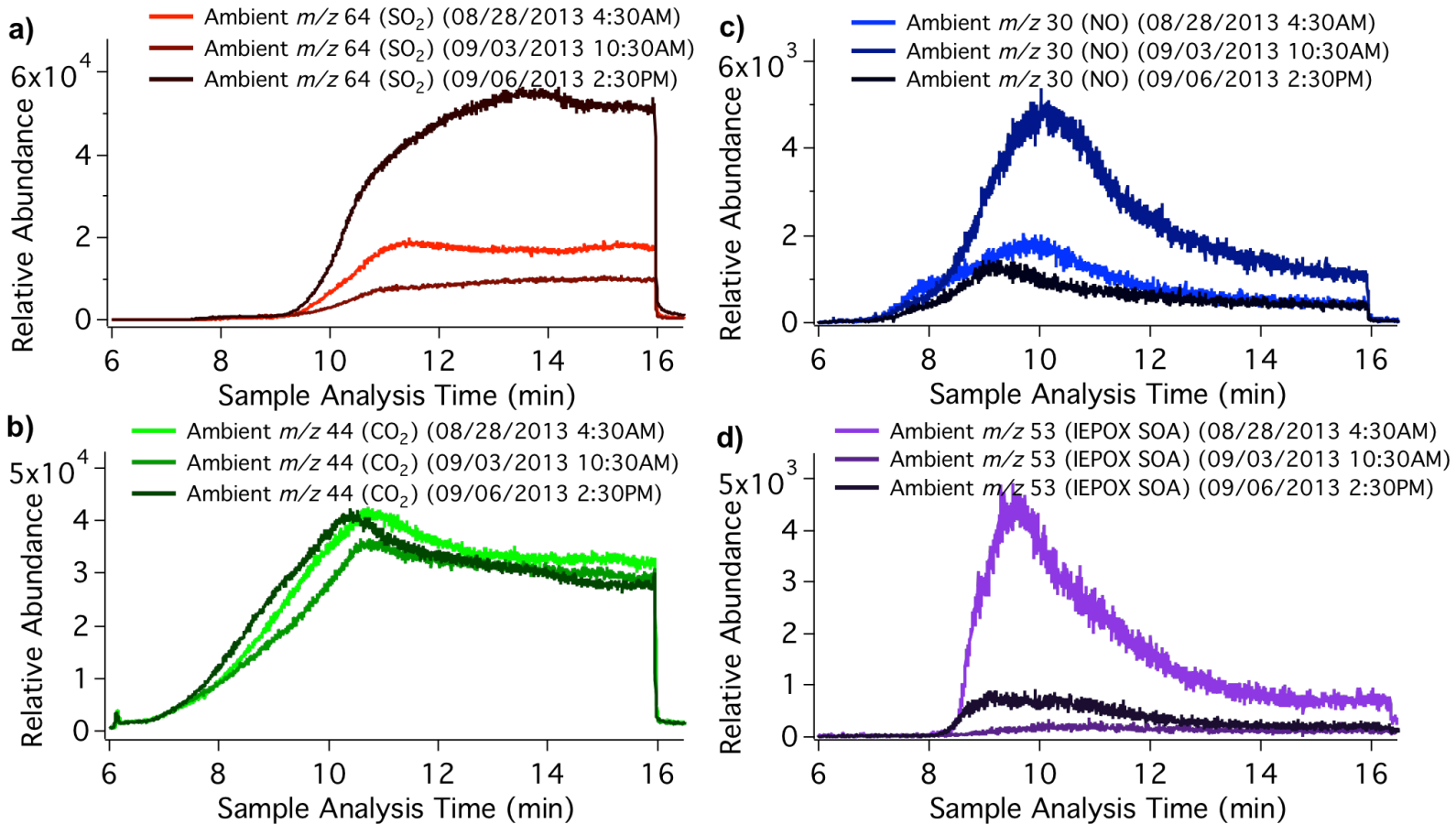

Figure S4. Among three different ambient samples from three different study periods, it is observed that (a) sulfate is highest in the late study period and the early sample appears to reach a maximum signal earlier in the analysis time $(\sim 11 \mathrm{~min})$ compared to the late study period $(\sim 14 \mathrm{~min})$. (b) Organics appear to have a more volatile component for the late study period, where $\mathrm{CO}_{2}$ signal increases earlier in the analysis time compared to the other two samples. Each sample reaches a maximum $\mathrm{CO}_{2}$ signal at slightly different injection period times. (c) Nitrate is highest in the mid sample period and each sample reaches a maximum at different points in the analysis time (early study period max at $\sim 10$ min with potentially a very volatile component at an earlier analysis time of $\sim 8 \mathrm{~min}$, mid study period max at $\sim 10 \mathrm{~min}$, and late study period max at $\sim 9.5 \mathrm{~min}$ ). (d) IEPOX SOA marker ion $\mathrm{m} / \mathrm{z} 53$ shows dramatic relative abundance variation throughout the study based on impact periods, but in general displays highest signal around $9.5 \mathrm{~min}$. 

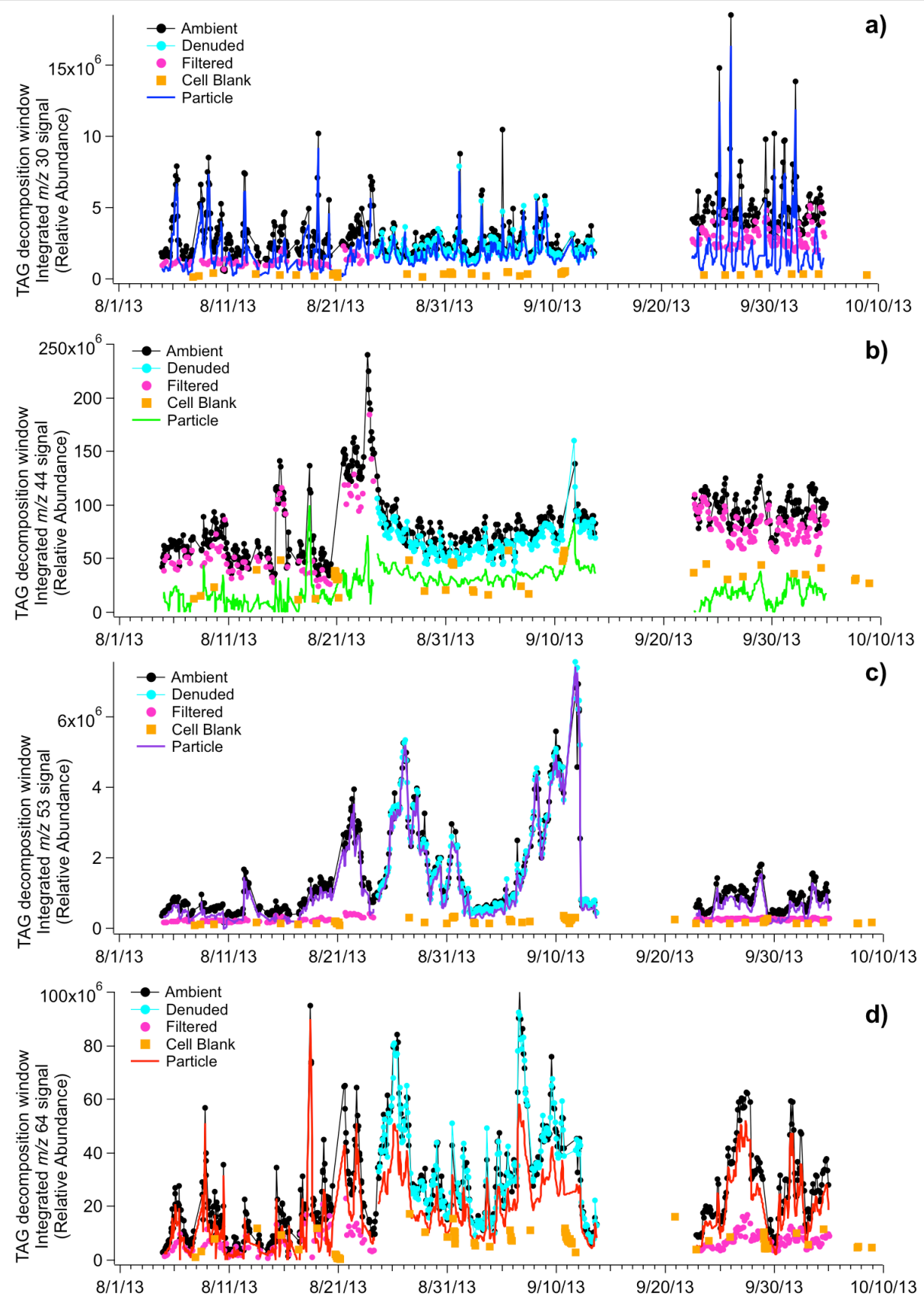

Figure S5. Field observations of major decomposition signals present in the TAG system during SLAQRS 2013 in East St. Louis, IL. Integrated ion signals during the sample injection period (6-16 min) are shown for (a) $\mathrm{m} / \mathrm{z} 30$, (b) $\mathrm{m} / \mathrm{z} 44$, (c) $\mathrm{m} / \mathrm{z} 53$, and (d) $\mathrm{m} / \mathrm{z} 64$. 

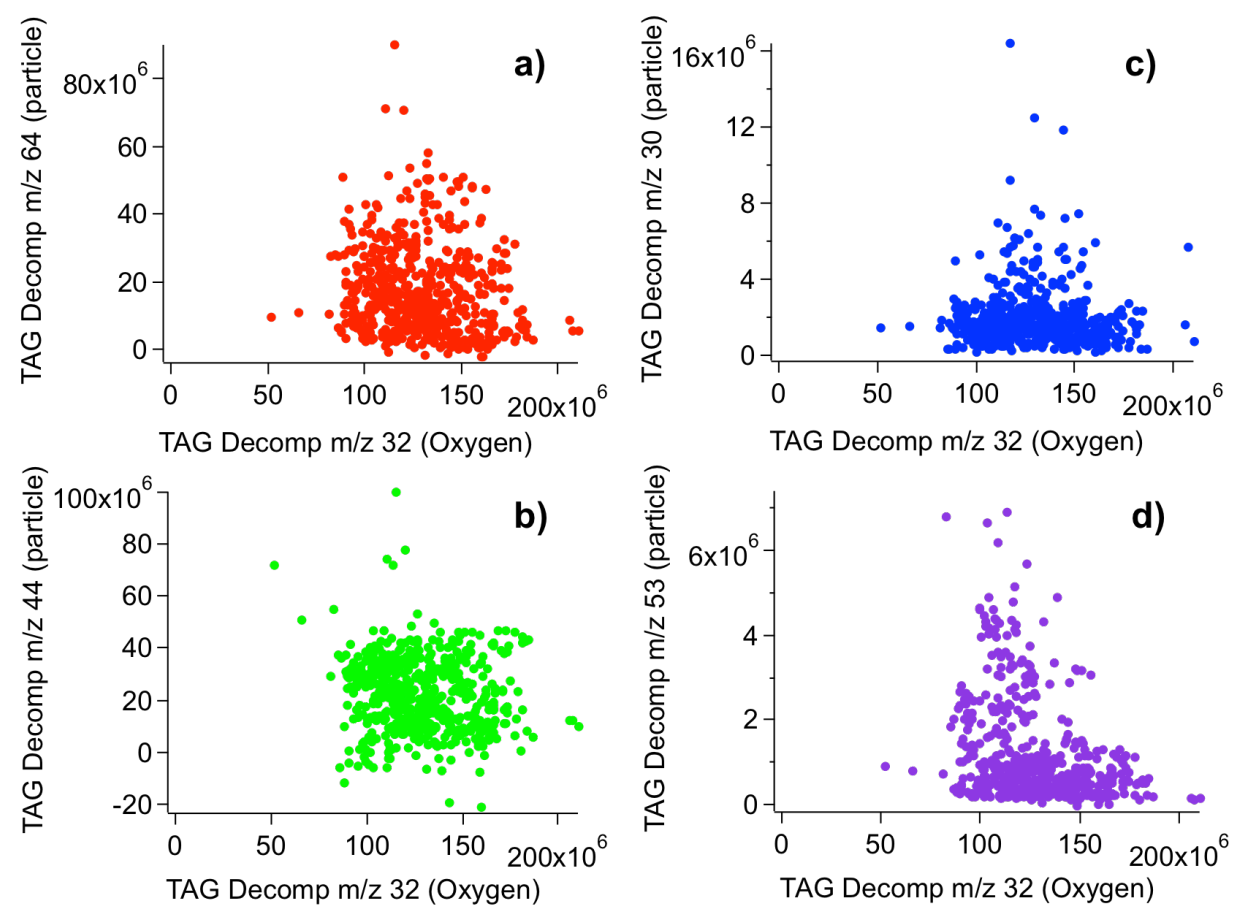

Figure S6. Relationship between decomposition window particle-only (a) $\mathrm{m} / \mathrm{z} 64$, (b) $\mathrm{m} / \mathrm{z} 44$, (c) $\mathrm{m} / \mathrm{z} 30$, and (d) $\mathrm{m} / \mathrm{z} 53$ with $\mathrm{m} / \mathrm{z} 32$ (Oxygen). Poor correlations are observed (R=-0.13, $-0.11,-0.02,-0.32$ for particle-only $\mathrm{m} / \mathrm{z} 64,44,30,53)$. 

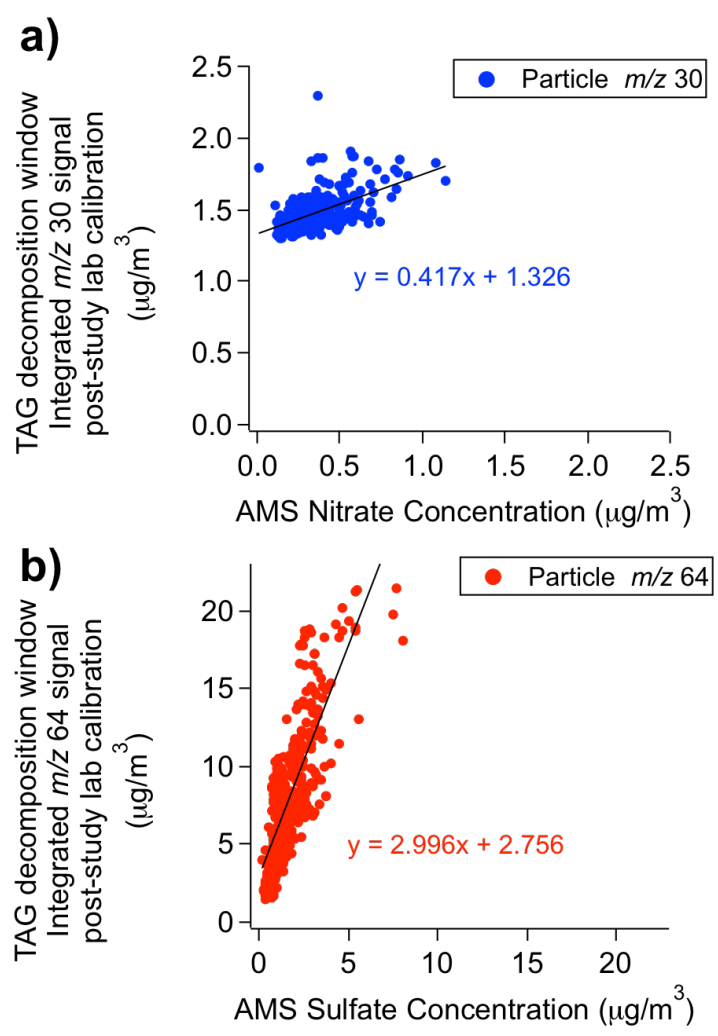

Figure S7. Applying post-study calibration standards to ambient SLAQRS TAG data to attempt calibration of (a) nitrate and (b) sulfate mass concentrations as observed with particle-only $\mathrm{m} / \mathrm{z} 30$ and $\mathrm{m} / \mathrm{z} 64$ integrated signals in the TAG decomposition window. Here it is observed that the there is a baseline offset of approximately $1.3 \mu \mathrm{g} / \mathrm{m}^{3}$ and a slope offset of a factor of 0.4 between TAG and AMS nitrate calibration. For sulfate there is a baseline offset of approximately $2.8 \mu \mathrm{g} / \mathrm{m}^{3}$ and a slope difference of a factor of 3 . 